\title{
The relationship between individual empowerment and health-promoting lifestyle among women NGOs in northern Iran
}

\author{
Fataneh Bakhshi ${ }^{1}$, Davoud Shojaeizadeh ${ }^{2}$, Roya Sadeghi ${ }^{3}$, Mohammad Hossein Taghdisi ${ }^{4}$, Saharnaz Nedjat ${ }^{5}$
}

${ }^{1}$ Ph.D. Candidate of Health Education and Promotion, Department of Health Education and Promotion, School of Public Health, International Campus, Tehran University of Medical Sciences, Tehran, Iran

${ }^{2} \mathrm{Ph} . \mathrm{D}$. of Health Education and Promotion, Professor, Department of Health Education and Promotion, School of Public Health, International Campus, Tehran University of Medical Sciences, Tehran, Iran

${ }^{3} \mathrm{Ph} . \mathrm{D}$. of Health Education and Promotion, Associate Professor, Department of Health Education and Promotion, school of Public Health, International Campus, Tehran University of Medical Sciences, Tehran, Iran

${ }^{4} \mathrm{Ph} . \mathrm{D}$. of Health Education and Promotion, Professor, Department of Health Education and Promotion, School of Public Health, Iran University of Medical Sciences, Tehran, Iran

${ }^{5}$ Ph.D. of Epidemiology and Biostatistics, Professor, Department of Epidemiology and Biostatistics, School of Public Health, Knowledge Utilization Research Center, Tehran University of Medical Sciences, Tehran, Iran

\section{Type of article: Original}

\begin{abstract}
Introduction: According to the health-promoting approach, people should be empowered such that they take responsibility for their health and follow a healthy lifestyle. Empowerment is a process in which people confront problems and tasks in their lives in order to better control them. This study was conducted to specify the relationship between individual empowerment and health-promoting lifestyle among women NGOs of northern Iran.

Methods: In this cross-sectional study, 290 women NGOs of Guilan Province were selected randomly using multistage cluster sampling, and were examined using the questionnaire of health-promoting lifestyle profile II and individual empowerment inventory scale. Data were analyzed using STATA 11 software via one-way ANOVA, Pearson correlation coefficient and multivariate linear regression.

Results: Both variables of individual empowerment and health-promoting lifestyle were of favorable status among the population under study. The highest score in individual empowerment belonged to the domain of social support and the highest score in lifestyle belonged to spiritual growth. A significant relationship was found between individual empowerment and health-promoting lifestyle $(\mathrm{p}<0.001)$. The highest correlation between individual empowerment and dimensions of health-promoting lifestyle was related to interpersonal relationships. In addition, it was specified that $21 \%$ of lifestyle variance could be explained by individual empowerment.

Conclusion: There is a relation between individual empowerment and health-promoting lifestyle. Individual empowerment is a predictive variable to have a health-promoting lifestyle. Therefore, by increasing individuals' empowerment, their healthy lifestyle can be promoted.

Keywords: Empowerment; Life style; NGOs
\end{abstract}

\section{Introduction}

Today, lifestyle is an important and significant strategy in which to prevent non-communicable diseases (NCDs) (1). Worldwide, over one third of mortality rate occurs due to an unhealthy lifestyle, and is the leading cause of prevalence of coronary diseases, hypertension, type II diabetes, tooth decay, stroke and a number of cancers (2). In Iran, diseases caused by an unhealthy lifestyle are the most common cause of morbidity and mortality (3). The

\section{Corresponding author:}

Dr. Roya Sadeghi, Department of Health Education and Promotion, School of Public Health, International campus, Tehran University of Medical Sciences, Tehran, Iran.

Tel: +98.2188955888, Fax:+98.2188989128, Email: sadeghir@tums.ac.ir

Received: July 18, 2016, Accepted: October 17, 2016, Published: February 2017

iThenticate screening: August 29, 2016, English editing: December 16, 2016, Quality control: January 12, 2017

(C) 2017 The Authors. This is an open access article under the terms of the Creative Commons Attribution-NonCommercialNoDerivs License, which permits use and distribution in any medium, provided the original work is properly cited, the use is non-commercial and no modifications or adaptations are made. 
World Health Organization (WHO) believes that most risk factors that are the major factors in mortality can be managed via changing and modifying lifestyle (4). In this regard, one of the objectives that will be determined by the WHO up to 2020 is to promote a healthy lifestyle among people. To this purpose, it is suggested that nations consider placing strategies on their agenda that are effective in promoting individual and social life (5), and reduce factors like improper physical activities, poor nutrition and drug abuse that direct the lifestyle towards failing health (4). One of these strategies is to increase peoples control on their life choices or their empowerment (6). In promoting health, it is believed that people are empowered such that they take the responsibility of their health and have a healthy lifestyle (7). In other words, due to the selective nature of behavior in lifestyle, it is necessary to pay attention to empowerment of each individual (8). This necessity increases in women, due to the relation between most gender-dependent problems and diseases including breast and uterus cancer, obesity, psychological problems and depression, stress and menopause (9). In general, limited evidence exists in this regard, due to the difficulty of measuring empowerment in society. Recently, several studies in Britain were conducted, on the relation between empowerment and health; however, they were not sufficiently reliable to be referred to, since their focus had not been on health outcomes. Therefore, there is a requirement to conduct studies to specify the relation between various levels of empowerment with individual and social health outcomes (10). Moreover, promoting women's empowerment using strategies of NGOs is an important factor in their lives, and provides an opportunity for them to choose, and this can bring about expected outcomes (11). The Health Companions Population (known as "Hamyaran") which operates under the supervision of the State Welfare Organization of Iran, is an NGO that operates to create opportunities and resources to promote objectives of social and health development. Empowerment of this population is one of the priorities of the State Welfare Organization. To this purpose, investigating empowerment dimensions of these people, and its relation to healthy lifestyle, can be helpful for future measures. This paper is part of a larger study on this issue that was conducted to find the relation between individual empowerment and lifestyles of women who are members of the Health Companions Population as a pilot study in northern Iran. The specific objectives of this study are to determine individual empowerment of subjects under study, to determine lifestyle status of subjects under study and to determine factors affecting lifestyle.

\section{Material and Methods}

\subsection{Sampling and Population under Study}

Sampling of this cross-sectional descriptive-analytic study was conducted from October 2015 to February 2016 among 290 NGOs of the Health Companions Population in Guilan Province. Participants were classified via random sampling and they were selected using Health Companions Population who functioned as volunteers under the supervision of the State Welfare Organization in Guilan Province.

\subsection{Inclusion \& Exclusion Criteria}

Inclusion criteria were over 6-month membership at intended population, willingness to participate in the study, and exclusion criteria were suffering from a diagnosed chronic disease and unwillingness to participate in the study.

\subsection{Data Collection Tools}

To collect data, a questionnaire with three sections of personal details (age, duration of membership at population, marital status, number of children, number of family members, job, housing, education, access to computer and the Internet, computer capabilities, and socio-economic status of the household), and a 37-item questionnaire of individual empowerment was employed in addition to the questionnaire of health-promoting lifestyle profile II. In the section of personal details filled by companions, to specify socio-economic status, the subjects were asked to rate socio-economic status from very high to very low. Anthropometric items including height, weight and blood pressure in this questionnaire were measured and recorded by administrator using the same measuring tape, scale and weights for all subjects. To measure empowerment, a researcher-made questionnaire with 37 questions was employed. The research group has previously provided this tool and its reliability and validity have been confirmed with Cronbach's alpha of 0.81 . This questionnaire measured individual empowerment of Health Companions in 8 fields including participation, motivation, cognitive thinking, critical thinking, intention, self-efficacy, perceived control and social support using 37 questions and, where the answers were provided, using 5-item Likert scale from strongly agree $(5$ scores $)$ to strongly disagree ( 1 score). Therefore, fields of participation, critical thinking and selfefficacy each with four questions, were scored between 4 and 20. Scores of motivation, intention and perceived control, with five questions, were between 5 and 25. Cognitive thinking, with three questions, was scored between 3 and 12 and social support, with seven questions, was scored between 7 and 35. Finally, the total score of individual empowerment was between 37 and 185 while calculating a separate score for each field. Higher scores show higher individual empowerment. In order to facilitate announcement of the results, it was decided to consider scores higher 
than average as favorable. To collect data related to healthy lifestyle in this study, the standard questionnaire of health-promoting lifestyle profile II was used. This questionnaire measured 6 dimensions of healthy lifestyle including nutrition, taking responsibility of health, interpersonal relations, spiritual growth, physical activity and stress management through 52 questions and they were scored via 4-item Likert scale of "never (1), sometimes (2), often (3), and always (4)." Four dimensions of nutrition, taking responsibility for health, interpersonal relations and spiritual growth (each with 9 questions with scoring range of 9-36) and two dimensions of physical activity and stress management (each with 8 questions with scoring range of 8-32) were scored. The range of total score for health-promoting lifestyle behavior is between 52 and 208 and for each dimension a separate score is considered. Taking higher scores in this questionnaire shows adopting healthier behavior and lifestyle. To facilitate announcement of the results, it was decided to consider scores higher than average as favorable. The standard questionnaire of health-promoting lifestyle profile II has been previously translated into Persian, and used in numerous studies. Validity and reliability of the Persian version of this questionnaire in Iran was confirmed by Mohammadi Zeidi et al. and verified with Cronbach's alpha of 0.82 and ICC of 0.91 (12).

\subsection{Data Analysis}

After collecting questionnaires and entering data into the computer, STATA 11 software was used to analyze them. To examine the significant difference between mean score of lifestyle dimensions based on levels of multimode qualitative variables (including marital status, economic status, and type of housing, job and education), one-way ANOVA was employed. In addition, Pearson correlation coefficient was used to examine the relation of various dimensions of health-promoting lifestyle with empowerment. In this study, individual empowerment and healthy lifestyle were considered as independent and dependent variables with significance level of $\mathrm{P}<0.05$. Multivariate linear regression was used to find the adjusted correlation between empowerment and healthy lifestyle. With regard to the high design effect of cluster sampling, survey command of STATA software was used for this analysis to consider design effect in estimation of variances. Criteria of including variables in these calculations were their correlation of less than 0.2 .

\subsection{Ethical Considerations}

This study has been registered at Tehran University of Medical Sciences with ethical code of 138416. Participating in this study was completely voluntary. Participants were assured that participating in this study would bring about no harm to them. Researchers pledged to complete all questionnaires without any name or details of subjects.

\section{Results}

\subsection{Socio-Demographic Factors of Respondents}

Of all participants, 33.2\% were between 30 and 39 years old. Duration of membership at Health Companions Population was less than 5 years for about $71 \%$ of respondents. Over half of the respondents were married and living in a 1-to-4-member family. Of respondents who had diplomas, there was $60.9 \%$, most of whom $(79.9 \%)$ were housekeepers. Of those who mentioned their socio-mental status as average, there was 67.6\%. Over half of these women had insufficient computer skills (Table 1).

\subsection{Individual Empowerment \& HPLP II Dimensions}

Of eight dimensions of individual empowerment, the highest score belonged to "social support" with an average of 27.7 and "motivation" with an average of 21.9, and the lowest score belonged to "self-efficacy" with an average of 14. Of six dimensions of health-promoting lifestyle, "spiritual growth" and "interpersonal relations" had the highest scores of 29.6 and 27.5 respectively and "physical activity" and "stress management" with average of 17 and 21.1 respectively had the lowest scores. Health-promoting lifestyle of companions with average of 144.3 considering the 0-100 scale of HPLP II was at a good level, and individual empowerment with average of 148.3 was high. As can be seen in Table 2, design effect range of all variables is over one and the highest value is observed in the domain of social support of individual empowerment (2.86). Results of correlation coefficient of individual empowerment with its total score, showed that perceived control has the highest correlation with total score of individual empowerment $(\mathrm{r}=0.76)$. The highest correlation of dimensions of health-promoting lifestyle with its total score, was related to spiritual growth $(\mathrm{r}=0.076)$. In addition, other dimensions showed a significant correlation with total score of empowerment and health-promoting lifestyle.

\subsection{Individual Empowerment in Association with Dimensions of Healthy Lifestyle}

Table 3 shows the results of correlation test (Pearson) between dimensions of individual empowerment and healthpromoting lifestyle. Most correlations are significant at $<0.05$. The highest correlation is related to empowerment 
with interpersonal relations $(\mathrm{p}<0.01, \mathrm{r}=0.42)$ and then the relation of perceived control with spiritual growth $(\mathrm{p}<0.01, \mathrm{r}=0.39)$. The lowest correlation is associated with the relation between perceived control and nutrition $(\mathrm{p}<0.05, \mathrm{r}=0.12)$. The relation of total score of individual empowerment with lifestyle is also high and significant $(\mathrm{p}<0.01, \mathrm{r}=0.36)$. According to this table, self-efficacy and total empowerment have a positive correlation with all dimensions of health-promoting lifestyle. Therefore, with a confidence level of $99 \%$, it can be said that there is a direct relationship between individual empowerment and health-promoting lifestyle in this group. Variables of duration of membership, marital status, having access to the Internet, socio-economic status and individual empowerment with $\mathrm{P}<0.02$ in simple regression test, entered multiple regression test. Coefficients of the regression effect of individual empowerment as independent variable on health-promoting lifestyle as dependent variable, showed that empowerment is a good predictor of health-promoting lifestyle. Coefficient of individual empowerment with healthy lifestyle is $21 \%$ that shows one unit increase in the individual empowerment score significantly increases health-promoting lifestyle score for 0.21 . Coefficients of the regression effect of other studied variables show that socio-economic status has a significant and reverse relationship with healthy lifestyle behavior.

Table 1. Respondents' characteristics in association with the mean score of the HPLP II dimensions through ANOVA $(\mathrm{n}=290)$

\begin{tabular}{|c|c|c|c|c|c|c|c|}
\hline \multirow[t]{2}{*}{ Variable } & \multicolumn{7}{|c|}{ HPLP II (p-value) } \\
\hline & Responsibility $^{\mathrm{a}}$ & $\begin{array}{l}\text { Physical } \\
\text { Activity }\end{array}$ & Nutrition $^{\mathrm{a}}$ & Spirituality $^{\mathrm{a}}$ & Relationship $^{a}$ & Stress $^{b}$ & Overall \\
\hline Age groups (year) & 0.011 & 0.347 & 0.112 & 0.006 & 0.084 & 0.399 & 0.056 \\
\hline $\begin{array}{l}\text { Duration of } \\
\text { membership (year) }\end{array}$ & $<0.001$ & 0.037 & 0.210 & 0.006 & 0.020 & 0.066 & 0.001 \\
\hline Marital status & 0.114 & 0.072 & 0.191 & 0.239 & 0.818 & 0.109 & 0.926 \\
\hline $\begin{array}{l}\text { Number of } \\
\text { children }\end{array}$ & 0.042 & 0.891 & 0.012 & 0.005 & 0.787 & 0.266 & 0.071 \\
\hline $\begin{array}{l}\text { Number of family } \\
\text { members }\end{array}$ & 0.768 & 0.784 & 0.562 & 0.837 & 0.661 & 0.074 & 0.662 \\
\hline Education & 0.692 & 0.553 & 0.759 & 0.535 & 0.745 & 0.721 & 0.650 \\
\hline Job & 0.987 & 0.608 & 0.866 & 0.193 & 0.067 & 0.788 & 0.251 \\
\hline House status & 0.844 & 0.016 & 0.611 & 0.559 & 0.375 & 0.504 & 0.341 \\
\hline $\begin{array}{l}\text { Computer } \\
\text { accessibility }\end{array}$ & 0.064 & 0.854 & 0.990 & 0.041 & 0.055 & 0.251 & 0.211 \\
\hline $\begin{array}{l}\text { Internet } \\
\text { accessibility }\end{array}$ & 0.165 & 0.026 & 0.570 & 0.003 & 0.027 & 0.988 & 0.031 \\
\hline $\begin{array}{l}\text { Computer ability } \\
\text { (Skill) }\end{array}$ & 0.421 & 0.036 & 0.269 & 0.891 & 0.890 & 0.280 & 0.567 \\
\hline $\begin{array}{l}\text { Subjective Social } \\
\text { Status }\end{array}$ & $<0.001$ & 0.002 & 0.006 & $<0.001$ & 0.009 & 0.021 & $<0.001$ \\
\hline BMI & 0.356 & 0.723 & 0.352 & 0.200 & 0.465 & 0.115 & 0.155 \\
\hline Systolic BP & 0.459 & 0.451 & 0.264 & 0.543 & 0.297 & 0.273 & 0.299 \\
\hline Diastolic BP & 0.252 & 0.127 & 0.570 & 0.464 & 0.286 & 0.435 & 0.540 \\
\hline
\end{tabular}

Attainable Score: $\mathrm{a}=9-36, \mathrm{~b}=8-32$ 
http://www.ephysician.ir

Table 2. Empowerment \& HPLP II dimensions score in the study population $(\mathrm{n}=290)$

\begin{tabular}{|l|l|l|l|l|l|}
\hline \multicolumn{2}{|l|}{ Dimension } & $\begin{array}{l}\text { Numbers of } \\
\text { questions }\end{array}$ & Range of scores & Mean (SD) & $\begin{array}{l}\text { Design } \\
\text { effect }\end{array}$ \\
\hline \multirow{4}{*}{ Empowerment } & Participation & 4 & $10-20$ & $16.8(0.19)$ & 2.14 \\
\cline { 2 - 6 } & Motivation & 5 & $10-25$ & $21.9(0.21)$ & 2.38 \\
\cline { 2 - 6 } & Cognitive thinking & 3 & $3-15$ & $20.3(0.23)$ & 1.71 \\
\cline { 2 - 6 } & Critical thinking & 4 & $7-20$ & $15.8(0.16)$ & 1.60 \\
\cline { 2 - 6 } & Intention & 5 & $12-25$ & $12.5(0.13)$ & 1.90 \\
\cline { 2 - 6 } & Self-efficacy & 4 & $7-20$ & $14(0.18)$ & 1.30 \\
\cline { 2 - 6 } & Perceived control & 5 & $7-25$ & $19.2(0.25)$ & 1.87 \\
\cline { 2 - 6 } & Social support & 7 & $12-35$ & $27.7(0.48)$ & 2.86 \\
\cline { 2 - 6 } & Overall (Empowerment) & 37 & $96-185$ & $148.3(1.54)$ & 2.95 \\
\hline \multirow{5}{*}{ Healthy lifestyle } & Responsibility & 9 & $9-36$ & $24.8(0.45)$ & 1.87 \\
\cline { 2 - 6 } & Physical activity & 8 & $8-32$ & $17(0.41)$ & 1.52 \\
\cline { 2 - 6 } & Nutrition & 9 & $13-35$ & $24.4(0.23)$ & 0.94 \\
\cline { 2 - 6 } & Spirituality & 9 & $13-36$ & $29.6(0.35)$ & 1.76 \\
\cline { 2 - 6 } & Relationship & 9 & $15-36$ & $27.5(0.29)$ & 1.24 \\
\cline { 2 - 6 } & Stress & 8 & $84-192$ & $144.3(1.53)$ & 1.46 \\
\cline { 2 - 6 } & Overall (HPLP II) & 52 & & & 1.5 \\
\hline
\end{tabular}

Table 3. Correlation between empowerment dimensions and health-promoting lifestyle $(n=290)$

\begin{tabular}{|l|l|l|l|l|l|l|l|l|l|}
\hline Variables & Participation & Motivation & $\begin{array}{l}\text { Cognitive } \\
\text { thinking }\end{array}$ & $\begin{array}{l}\text { Critical } \\
\text { thinking }\end{array}$ & Intention & $\begin{array}{l}\text { Self- } \\
\text { efficacy }\end{array}$ & $\begin{array}{l}\text { Perceived } \\
\text { control }\end{array}$ & $\begin{array}{l}\text { Social } \\
\text { support }\end{array}$ & $\begin{array}{l}\text { Overall } \\
\text { (Empowerment) }\end{array}$ \\
\hline Responsibility & $0.24^{* *}$ & $0.18^{* *}$ & $0.14^{*}$ & $0.15^{*}$ & $0.17^{* *}$ & $0.26^{* *}$ & $0.19^{* *}$ & $0.17^{* *}$ & $0.27^{* *}$ \\
\hline $\begin{array}{l}\text { Physical } \\
\text { activity }\end{array}$ & 0.11 & -0.053 & 0.016 & 0.089 & 0.096 & $0.24^{* *}$ & $0.13^{*}$ & 0.092 & $0.13^{*}$ \\
\hline Nutrition & 0.11 & 0.047 & 0.007 & 0.069 & 0.092 & $0.13^{*}$ & $0.12^{*}$ & $0.13^{*}$ & $0.13^{*}$ \\
\hline Spirituality & $0.28^{* *}$ & $0.17^{* *}$ & 0.077 & $0.21^{* *}$ & $0.20^{* *}$ & $0.32^{* *}$ & $0.39^{* *}$ & $0.26^{* *}$ & $0.35^{* *}$ \\
\hline Relationship & $0.30^{* *}$ & $0.25^{* *}$ & $0.17^{* *}$ & $0.29^{* *}$ & $0.31^{* *}$ & $0.35^{* *}$ & $0.36^{* *}$ & $0.28^{* *}$ & $0.42^{* *}$ \\
\hline Stress & $0.20^{* *}$ & 0.046 & 0.067 & 0.085 & $0.15^{*}$ & $0.26^{* *}$ & 0.11 & $0.19^{* *}$ & $0.20^{* *}$ \\
\hline $\begin{array}{l}\text { Overall } \\
\text { (HPLP II) }\end{array}$ & $0.29^{* *}$ & $0.19^{* *}$ & 0.11 & $0.21^{* *}$ & $0.26^{* *}$ & $0.35^{* *}$ & $0.29^{* *}$ & $0.28^{* *}$ & $0.36^{* *}$ \\
\hline
\end{tabular}

${ }^{*} \mathrm{p}<0.05,{ }^{* *} \mathrm{p}<0.01$

\section{Discussion}

Various social, economic and environmental factors are associated with health-promoting lifestyle behavior. Although finding the relation between these factors and health is not an arduous task, it is often overlooked by health staff. According to the results of this study, there is a positive and significant relationship between individual empowerment and health-promoting lifestyle. Of dimensions of empowerment, seven dimensions of participation, motivation, critical thinking, intention, self-efficacy, perceived control and social support are positively and significantly related to health-promoting lifestyle. Of demographic details of the subjects, there is a significant relationship between duration of membership at Health Companions Population, socio-economic status and having access to the Internet, with health-promoting lifestyle. On the other hand, duration of membership and socioeconomic status were significantly related to individual empowerment. In explaining these results, it can be said that, as duration of membership at Health Companions Population increases, people's empowerment also increases and are more inclined to follow health promoting lifestyles. As Laverack stated in his study, individual and social empowerment of people can improve health-related outcomes via the effect of factors like participation, management, etc. (13). Socio-economic status can also be a factor to empower individuals by developing freedom of choice and action, and therefore, better and more compliance with health-promoting behavior $(14,15)$. In examining various dimensions of health-promoting lifestyle, the highest score was related to dimensions of spiritual growth and interpersonal relations, which complies with results of other studies $(16,17)$. In addition, the lowest score was related to dimensions of physical activity and stress management. Lower mean score of physical activity and stress management complies with various studies, including the study by Malakouti, Sousa and Cao (18-20). However, in the study by Enjezab et al., on middle-aged women in Yazd, stress management was of a high score (16). This incompliance can be justified by differences in occupational and social features of targeted communities. In terms of 
individual empowerment, the highest score obtained was related to dimensions of motivation and social support. This finding complies with results of the study by Hall (21). In the study by Nedjat, social support and dependence were also of high scores (22). Average total score of calculated individual empowerment, shows that participants were able to obtain $80.2 \%$ of total score of empowerment inventory and it is a relatively high percent that shows good individual empowerment of these people. This value has been reported to be different in various studies. Sa'di (2014) reported empowerment of rural women to be $63.3 \%$ (23). In the study by Kiani, women's empowerment to decide for pregnancy, was reported to be $54.3 \%$ (15). Soares estimated the total average of individual empowerment to be $77.83 \%$ (24). These differences can be related to differences in the target population of those studies. Higher empowerment in this study can be due to the voluntary nature of NGOs and participation of these women in various courses of readiness for cooperation. On the other hand, it appears that people who are more empowered seek for voluntary activities in society. Total mean score of health-promoting lifestyle shows $69.4 \%$ of total score of the inventory, i.e., higher than average scored by participants. These results comply with findings of the study by Enjezab on women of Yazd (16). The similarities in these results are due to selecting middle-aged women as subjects in both studies. However, in most studies where samples were selected from other groups such as teachers, students or nurses, this value was reported to be lower $(9,25-27)$. Results of this study on the relationship between various dimensions of empowerment and health-promoting behavior show that there is a significant and positive relationship between dimensions of participation, motivation, critical thinking, intention, self-efficacy, perceived control and social support with health-promoting lifestyle behavior. In various studies, different dimensions are considered for empowerment that are more or less identical. Results from investigating the relationship between these dimensions and lifestyle show that health promotion is completely affected by community empowerment ( 28 , 29). In various statements of the WHO, the effect of empowerment on health promotion and healthier lifestyle are emphasized via individuals' participation in health programs and health-oriented decision-making (30-33). In this regard, there is evidence on the effect of empowerment on mental health, self-efficacy and self-confidence of people $(13,34-37)$. In two studies, it is shown that participating in different social groups and programs leads to health promotion and healthy lifestyle behavior $(13,38)$. The effect of individual empowerment on health-promoting lifestyle was positive and significant, such that as empowerment increased, health-promoting lifestyle developed for $21 \%$ of the study population. In explaining this finding, it can be said that due to the dependency of lifestylepromoting behavior to decision-making of people $(13,39)$, all factors affecting decision-making and choices of individuals, comprise following healthier behavior in their lives. Although no study was found that directly investigated these two variables, some studies based on strategies of increasing patients' compliance with healthoriented regimes, focus their attention on empowering those people (40-43). For instance, in 2011 McCorkle showed that caring patients with the aim of empowerment of cancer patients can result in increased self-efficacy and improve their quality of life and promote a healthier life (44). The relationship between dimensions of individual empowerment and health-promoting lifestyle, shows the significance of most of these correlations. The highest correlation is found between individual empowerment and interpersonal relations of health-promoting lifestyle and then between perceived control and spiritual growth. Participation as one of the bases of empowerment, requires creating appropriate interpersonal relations. In various groups and populations, due to continuous and permanent interactions, interpersonal relations are strengthened (45). In his study, Hatzidimitriadou reported that membership in a group increases the sense of control and individual empowerment (46). In other words, volunteering in NGOs, results in increased positive attitudes, development of ethics and accountability in the community (47). Since the population of this study were a group of volunteer women who were members of an NGO, deep interactions and interpersonal relations, the spirit of participation in various activities and capability of critical thinking and decision making are considered as part of their routine activities. This will strengthen individual empowerment and as a result, their community empowerment, and it puts them among empowered people of the society. There is also evidence for the effect of empowerment on the ability of decision-making (48). In addition, findings of various studies show the relationship between empowerment and health outcomes in individuals and groups (49). Therefore, currently one of the effective strategies for comprehensive and sustainable development, is to employ people's empowerment and participation in all dimensions. The major tool to reach this goal is to establish NGOs, based on the needs and abilities of various groups in the essential and assorted issues, to implement development plans (50). Therefore, most countries encourage their people to participate in voluntary activities with the aim of promoting environmental or social objectives (51).

\section{Conclusions}

Findings of this study, showed that by increase in empowerment of women under study, their health-promoting lifestyle also improved, and dimensions of social support, motivation and participation had the major role in increasing individual empowerment. Functional importance of these findings, is that some evidence for the effect of 
empowerment on healthy lifestyle was obtained that was not directly investigated earlier. It is suggested to design interventions to increase the dimensions stated, in order to promote individual empowerment in society. Therefore, while having an empowered community, we will also see a healthier lifestyle. Conducting a complementary study on the relationship between individual empowerment and healthy lifestyle on non-NGO women with a similar methodology, can be a good path for future studies on this issue.

\section{Acknowledgments:}

This study is part of a Ph.D. dissertation of Health Education and Promotion to the grant number of 9123489002. Authors of this study, greatly appreciate the reverend research deputy of International Campus of Tehran University of Medical Sciences for approval and financial support of this project, as well as all "Hamyaran" of Guilan Province known as a group who were active volunteers at the NGO, and sincerely participated in various stages of this study.

\section{Conflict of Interest:}

There is no conflict of interest to be declared.

\section{Authors' contributions:}

All authors contributed to this project and article equally. All authors read and approved the final manuscript.

\section{References:}

1) Maheri AB, Bahrami MN, Sadeghi R. The Situation of Health-Promoting Lifestyle among the Students Living in Dormitories of Tehran University of Medical Sciences, Iran. Journal of Health and Development. 2013; 1(4): 275-86.

2) Fayazbakhsh A, Khajeh KR, Soleymani NM, Rahimi F, Jahangiri L, Heydari S, et al. The Internet Using And Health: Students' knowledge, Attitude And Lifestyle Related To The Internet. Hakim. 2011; 14(2): 96105.

3) Tol A, Tavassoli E, Shariferad GR, Shojaezadeh D. The relation between health-promoting lifestyle and quality of life in undergraduate students at school of health, Isfahan University of Medical Sciences. Health System Research. 2011; 7(4).

4) Naghibi F, Golmakani N, Esmaily H, Moharari F. The relationship between life style and the health related quality of life among the girl students of high schools in Mashhad, 2012-2013. Iranian Journal of Obstetrics, Gynecology and Infertility. 2013; 16(61): 9-19.

5) Monahan FD, Phipps WJ. Phipps' medical-surgical nursing: health and illness perspectives: Recording for the Blind \& Dyslexic; 2008.

6) Laverack G. Health Promotion Practice: Building Empowered Communities: Building Empowered Communities: McGraw-Hill International; 2007.

7) Mohamadian H, Eftekhar Ah, Taghdisi Mh, Mousavi Ga, Sabahi Bm. Psychometric properties of the health-promoting lifestyle profile (HPLP II) in a sample of Iranian adolescents. Payesh. 2013; 12(2): 167176.

8) Abdi J, Eftekhar H, Mahmoodi M, Shojayzadeh D, Sadeghi R. Lifestyle of Employees working in Hamadan Departments: An Application of the Trans-Theoretical Model. Journal of Education and Community Health. 2014; 1(1): 46-54. doi: 10.20286/jech-010146.

9) Beser A, Bahar Z, Buyukkaya D. Health promoting behaviors and factors related to lifestyle among Turkish workers and occupational health nurses' responsibilities in their health promoting activities. Ind Health. 2007; 45(1): 151-9. doi: 10.2486/indhealth.45.151. PMID: 17284887.

10) Woodall J, Raine G, South J, Warwick-Booth L. Empowerment \& health and well-being: evidence review. Project Report. Centre for Health Promotion Research, Leeds Metropolitan University. 2010. Available from: http://eprints.leedsbeckett.ac.uk/id/eprint/2172.

11) Magar V. Empowerment approaches to gender-based violence: women's courts in Delhi slums. Women's Studies International Forum. 2003; 26(6): 509-23. doi: 10.1016/j.wsif.2003.09.006.

12) Zeidi IM, Hajiagha AP, Zeidi BM. Reliability and validity of Persian version of the health-promoting lifestyle profile. Journal of Mazandaran University of Medical Sciences. 2012; 22: 103-13.

13) Laverack G. Improving health outcomes through community empowerment: a review of the literature. Journal of Health, Population and Nutrition. 2006; 24(1): 113-20. PMID: 16796158.

14) Edge S, Newbold KB, McKeary M. Exploring socio-cultural factors that mediate, facilitate, \& constrain the health and empowerment of refugee youth. Social Science \& Medicine. 2014; 117: 34-41. doi: 10.1016/j.socscimed.2014.07.025. PMID: 25036014. 
15) Kiani Z, Simbar M, Dolatian M, Zayeri F. Correlation between Social Determinants of Health and Women's Empowerment in Reproductive Decision-Making among Iranian Women. Glob J Health Sci. 2016; 8(9): 312-21. doi: 10.5539/gjhs.v8n9p312. PMID: 27157184, PMCID: PMC5064082.

16) Enjezab B, Farajzadegan Z, Taleghani F, Aflatoonian A, Morowatisharifabad MA. Health promoting behaviors in a population-based sample of middle-aged women and its relevant factors in Yazd, Iran. Int J Prev Med. 2012; 3(Suppl1): S191-8. PMID: 22826765, PMCID: PMC3399308.

17) Flattery M, Salyer J, Maltby M, Joyner P, Elswick R. Lifestyle and health status differ over time in longterm heart transplant recipients. Prog Transplant. 2006; 16(3): 232-8. doi: 10.1177/152692480601600308. PMID: 17007158 .

18) Sousa P, Gaspar P, Vaz DC, Gonzaga S, Dixe MA. Measuring Health-Promoting Behaviors: CrossCultural Validation of the Health-Promoting Lifestyle Profile-II. Int J Nurs Knowl. 2015; 26(2): 54-61. doi: 10.1111/2047-3095.12065. PMID: 25389054.

19) Cao WJ, Chen CS, Hua Y, Li YM, Xu YY, Hua QZ. Factor analysis of a health-promoting lifestyle profile (HPLP): Application to older adults in Mainland China. Arch Gerontol Geriatr. 2012; 55(3): 632-8. doi: 10.1016/j.archger.2012.07.003. PMID: 22854282.

20) Malakouti J, Sehhati F, Mirghafourvand M, Nahangi R. Relationship between Health Promoting Lifestyle and Perceived Stress in Pregnant Women with Preeclampsia. J Caring Sci. 2015; 4(2): 155. doi: 10.15171/jcs.2015.016. PMID: 26161369, PMCID: PMC4484990.

21) Hall M. The effect of comprehensive performance measurement systems on role clarity, psychological empowerment and managerial performance. Accounting, Organizations and Society. 2008; 33(2): 141-63. doi: 10.1016/j.aos.2007.02.004.

22) Nedjat S, Majdzadeh R, Kheiltash A, Jamshidi E, Yazdani S. Social capital in association with socioeconomic variables in Iran. Social indicators research. 2013; 113(3): 1153-70.

23) Sadi H, Jalilian S, Yaghubifarani A. The Influence of Home based Businesses on Rural Women's Social Empowerment. Sociology of women (journal of woman and society). 2014; 5(3): 85-107.

24) Soares MF, Ferreira RC, Pazzini CA, Travassos DV, Paiva SM, Ferreira EFE. Individual and collective empowerment and associated factors among Brazilian adults: a cross-sectional study. BMC Public Health. 2015; 15: 775. doi: 10.1186/s12889-015-2113-7. PMID: 26264129, PMCID: PMC4533936.

25) Baghianimoghadam M, Ehrampoush M, Ardian N, Soltani T. A research about health promoting activities (lifestyle) at employees. tkj. 2013; 5(3): 79-87.

26) Alkhawaldeh O. Health promoting lifestyles of Jordanian university students. International Journal of Advanced Nursing Studies. 2014; 3(1): 27-31.

27) Heidari F, Mohammad Khan Kermanshahi S, Vanaki Z. The effect of a supportive health promotion program on the lifestyle of premenopause teachers. FEYZ. 2013; 17(1): 14-24.

28) Laverack G, Labonte R. A planning framework for community empowerment goals within health promotion. Health Policy Plan. 2000; 15(3): 255-62. doi: 10.1093/heapol/15.3.255. PMID: 11012399.

29) James W, Gary R, Jane S, Louise WB. empowerment and health \& well-being: Yorkshire \& Humber Public Health Observatory. 2010.

30) World Health Organization, editor Declaration of Alma-Ata. Geneva: World Health Organization. International Conference on Primary health Care Alma-Ata. Accessed 14th; 1978. Available from: http://www who int/publications/almaata_declaration_en pdf.

31) World Health Organization. Sundsvall statement on supportive environments for health, 1991, Sundsvall, Sweden; 1992.

32) Promotion $\mathrm{ICoH}$, Organization WHO. The Jakarta declaration on leading health promotion into the 21 st century: adopted at the Fourth International Conference on Health Promotion, 1997, Jakarta, Republic of Indonesia: Verlag für Gesundheitsförderung Conrad; 1997.

33) World Health Organization. Ottawa Charter for Health Promotion. Geneva: World Health Organization; 1986, 2009.

34) Neighbors HW, Braithwaite RL, Thompson E. Health promotion and African-Americans: from personal empowerment to community action. Am J Health Promot. 1995; 9(4): 281-7. doi: 10.4278/0890-11719.4.281. PMID: 10150731.

35) Fisher BJ, Gosselink CA. Enhancing the efficacy and empowerment of older adults through group formation. J Gerontol Soc Work. 2008; 51(1-2): 2-18. doi: 10.1080/01634370801967513. PMID: 18826065 . 
36) Jacobs G. Imagining the flowers, but working the rich and heavy clay: participation and empowerment in action research for health. Educational Action Research. 2006; 14(4): 569-81. doi: 10.1080/09650790600975809.

37) Aday RH, Kehoe G. Working in old age: benefits of participation in the senior community service employment program. Journal of Workplace Behavioral Health. 2008; 23(1-2): 125-45. doi: $10.1080 / 15555240802189521$.

38) Wallerstein N. What is the evidence on effectiveness of empowerment to improve health? Copenhagen, Denmark, World Health Organization, Regional Office for Europe, Health Evidence Network, 2006. 37 p. (Health Evidence Network Report).

39) Ochieng B. Factors affecting choice of a healthy lifestyle: implications for nurses. Br J Community Nurs. 2006; 11(2): 78-81. doi: 10.12968/bjen.2006.11.2.20445. PMID: 16493312.

40) Maunsell E, Lauzier S, Brunet J, Pelletier S, Osborne RH, Campbell HS. Health-related empowerment in cancer: Validity of scales from the Health Education Impact Questionnaire. Cancer. 2014; 120(20): 3228 36. doi: 10.1002/cncr.28847. PMID: 24988944.

41) Tangney JP, Baumeister RF, Boone AL. High self-control predicts good adjustment, less pathology, better grades, and interpersonal success. J pers. 2004;72(2): 271-324. doi: 10.1111/j.0022-3506.2004.00263.x. PMID: 15016066.

42) Baljani E, Salimi S, Rahimi J, Amanpour E, Parkhashjou M, Sharifnejad A, et al. The effect of education on promoting self efficacy in patients with cardiovascular disease. J Kermanshah Univ Med Sci. 2012; 16(3): 227-35.

43) Sadeghi M, Ebrahimi H, Bazghaleh M. Relationship between empowerment with dimensions of quality of life and some related factors in patients with type 2 diabetes in the Shahroud city, 2013. Journal of Clinical Nursing and Midwifery. 2015; 3(4): 29-38.

44) McCorkle R, Ercolano E, Lazenby M, Schulman-Green D, Schilling LS, Lorig K, et al. Self- management: Enabling and empowering patients living with cancer as a chronic illness. CA Cancer J Clin. 2011; 61(1): 50-62. doi: 10.3322/caac.20093. PMID: 21205833, PMCID: PMC3058905.

45) Laverack G. A-z of health promotion. UK: Palgrave Macmillan; 2013.

46) Hatzidimitriadou E. Political ideology, helping mechanisms and empowerment of mental health selfhelp/mutual aid groups. Journal of community \& applied social psychology. 2002; 12(4): $271-85$ doi: 10.1002/casp.681.

47) Catano VM, Pond M, Kevin Kelloway E. Exploring commitment and leadership in volunteer organizations. Leadership \& Organization Development Journal. 2001; 22(6): 256-63. doi: 10.1108/01437730110403187.

48) Pratchett L, Durose C, Lowndes V, Smith G, Stoker G, Wales C. Empowering communities to influence local decision making: A systematic review of the evidence. London, UK: Communities and Local Government Publications; 2009.

49) O'Mara-Eves A, Brunton G, McDaid G, Oliver S, Kavanagh J, Jamal F, et al. Community engagement to reduce inequalities in health: a systematic review, meta-analysis and economic analysis. Public Health Research. 2013; 1(4). doi: 10.3310/phr01040. PMID: 25642563.

50) Baloui E, Bagherzadeh MR, Tabari M, Roshanbakhsh F. The survey of empowerment of NGO's organization in Mazandaran. Quarterly Journal of Productively Management. 2011; 5(18): 99-123.

51) The Canadian International Development Agency. Engaging Stakeholders And Business-Ngo Partnerships In Developing Countries: Maximizing An Increasingly Important Source of Value. Canada: CICR; 1999. 